\title{
Arte e Programas de Inteligência Artificial: GPT-2, GPT-3, Wu Dao $2.0^{1}$
}

Philippe Willemart"

\section{Resumo}

O texto faz parte de uma pesquisa tentando relacionar o estudo do manuscrito com a inteligência artificial. A partir da roda da escritura, verifico em que medidas os programas GPT e Wu Dao 2.0 podem seguir ou não a roda. Se para os GPT 2 e 3, parece obvio que não tendo subjetividade, é impossível percorrer a roda, ficamos em dúvida quanto ao programa chinês devido à enorme capacidade jamais visto até hoje.

Palavras-chaves: GPT-2, GPT-3, Wu Dao 2.0, genética, processos de criação.

\section{Introduç̧ão}

Gostaria, em primeiro lugar, de agradecer a Fabiane Burlamaque e Miguel Rettenmaier pelo convite que reforça os laços da Universidade de Passo Fundo com a APCG. Não vou falar de Josué Guimarães diretamente nem de seus manuscritos, mas da relação mais ampla de nossos autores com a Inteligência artificial.

A palestra de hoje é a terceira de uma pesquisa que iniciei em 2019 quando tentava relacionar a inteligência artificial com a arte de escrever ou de compor uma melodia. Logo, me deparei com várias tentativas de vários robôs de igualar o homem, mas nenhuma me convenceu.

\footnotetext{
Prof. Titular em literatura Francesa da Universidade de São Paulo, pesquisador IA do CNPq. Autor de várias obras no Brasil (Edusp, Iluminuras, Ateliê, Perspectiva) e no Exterior (L'Harmattan-Paris, Liber-Montréal, Peter Lang-Oxford). Colaborou à criação da Associação dos Pesquisadores em Crítica Genética (APCG).
} 
A primeira contribuição saiu na revista Signum da Universidade de Londrina. ${ }^{2}$

$\mathrm{Na}$ segunda palestra que foi no $V$ simpósio de crítica genética e arquivologia em Teresina, concluía com essas seis resoluções:

1. Não temos acesso direto aos cérebros dos escritores, mas apenas aos frutos de sua atividade na escritura contrariamente aos robôs.

2. Parecido com a máquina que auto aprende pela insistência, o escritor constrói seu estilo ou sua forma repetindo processos de criação. O estilo é nada mais do que a soma dos algoritmos que criados aos poucos, se impõem. $\mathrm{O}$ algoritmo não existe para a arte em processo, pois só se revelará no final do processo; o exercício da arte é uma luta contínua contra os algoritmos existentes.

3. Ninguém nasce escritor, mas a ação de escrever, pintar, esculpir, inventar melodia, criará no cérebro "zonas [...] com uma arquitetura específica dedicada a essas tarefas" A qualidade primária será baseada em sua abertura para o mundo em que vive e não em um presente intrínseco ou em um DNA privilegiado.

4. Cada novo evento repercute aleatoriamente em todas as redes neuronais para o escritor e não numa rede determinada como no robô.

5. No manuscrito, as rasuras não são "esmagadas" como os erros no robô, já que as palavras ou expressões rasuradas voltam inteiras ou metaforizadas. Rasurar consistirá não em encontrar a curva certa ou a linha certa da história, que só existirá no final, mas em definir cada ponto da curva.

6. Na literatura, o sentido será deduzido a partir de uma morfologia desconhecida do escritor que ligará o número de pontos no manuscrito enquanto o robô saberá o caminho de antemão. Para o robô, o limite das vias possíveis será compensado pela segurança da via a seguir, enquanto o escritor deve combinar vias possíveis com a incerteza do autor.

Parecia certo até hoje que um robô, mesmo sendo capaz de imitar uma melodia musical, não tem o mesmo grau de competência para reproduzir o estilo de um compositor ou criar uma obra que se destaque por seu valor artístico.

No entanto, algumas experiências do Programa de Inteligência de Artistas e Máquinas do Google ${ }^{3}$, a chegada de uma supermáquina, o GPT-3 em $2020,{ }^{4} \mathrm{e}$ um modelo de linguagem hiperpoderoso chinês, o Wu Dao 2.0 em 2021, nos pedem 
para matizar essa dificuldade e considerar de outra maneira a relação entre $o$ artista e a máquina

Onde obter critérios para dizer que um texto, seja de um robô ou de um ser humano, é literário ou não, artístico ou apenas de comunicação?

1. Em primeiro lugar, verei os fatores a favor e os contra o Programa do Google (AMI) e do GPT-3 em relação a escritura literária.

2. Em segundo lugar, examinaremos as últimas performers do GPT-3 salientadas por Frederik Bussler, fundador da Obviamente $I A$, uma empresa de marketing baseada na IA

3. Em terceiro lugar, vou confrontar os processos de criação de um texto inventado por um robô com as instâncias da roda de escritura, e verificar se o robô consegue segui-los como o escritor.

\section{O Robô e Literatura}

Para separar os proponentes e os adversários, tomarei como critério o percurso possível ou não da roda da escritura. (Willemart, 2019, 99) Máquina eficaz que determina o movimento nas cinco instâncias, as do escritor, do scriptor, do narrador, do primeiro leitor e finalmente do autor, uma caminhada que é realizada no final de cada rasura substituída ou não. Cada instância é anexada a uma pulsão específica e, portanto, à dimensão inconsciente do gesto de escrever, excluir, adicionar, reler ou confirmar.

\section{A roda da escritura para 0 escritor}

Como o escritor vive as pulsões durante a criação?

\section{A roda da escritura agindo em cada rasura}

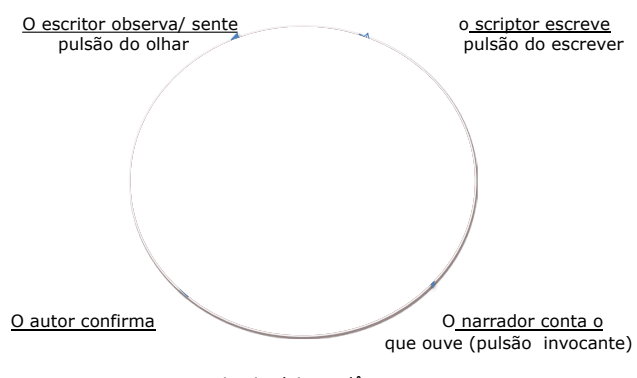

o primeiro leitor relê e rasura

O scriptor, aquele que se submete à linguagem e ouve as ansiedades, tristezas e alegrias de seus próximos e de sua comunidade, sente, observa e vê alguma coisa quando entende como responder a essas demandas através do enredo de seus personagens?

O narrador à procura de uma boa história escuta não somente seus contemporâneos, mas as palavras ou expressões escritas.

O primeiro leitor escutando melhor ainda, rasura e substitui palavras, parágrafos e até capítulos inteiros

Quando o autor empurrado sem ele souber pelo texto definitivo, imaginário 
até lá, decide passar para a próxima frase ou ao próximo capítulo

\section{A roda da escritura para o robô}

Um robô poderia percorrer as instâncias da roda da escritura? No início, acreditava o percurso impossível, mas consultando alguns resultados, acredito que a máquina ou o programa consegue em parte.

A escolha do assunto ou do objetivo sempre caberá ao engenheiro que irá construí-lo ou que tem a ideia.

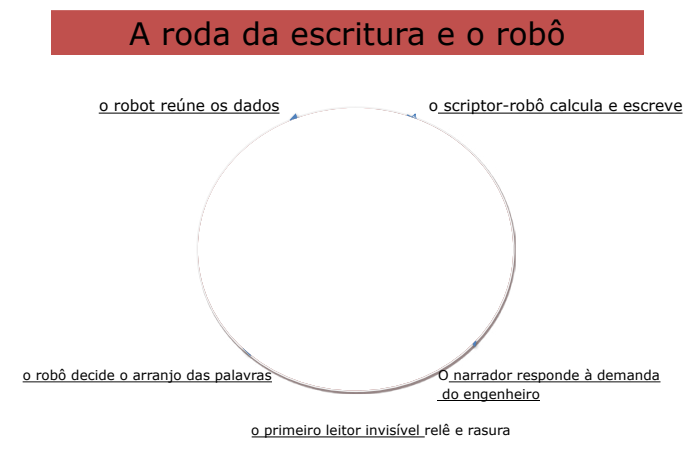

1. O scriptor-robô se submeterá aos bilhões de dados que serão carregados por seu criador, mas não saberá a quais pedidos responder, a menos que mais uma vez, seu engenheiro proponha um objetivo.

2. O narrador-robô poderá contar uma história, mas sem rasura nem hesitações já que sabe onde quer chegar, diferentemente do escritor que sabe vagamente.
Ignorando o passar do tempo, o robô resolve imediatamente o problema na velocidade da luz. (Sadin, 2015, 64)

3. Quarta instância, ao reler o texto, o robô pode notar um erro comparando-o com o objetivo perseguido. Neste caso, ele empregará a retro-propagação e usará esse erro para ajustar os parâmetros que no ser humano seriam atribuições da rede neural. (com uma rede antagonista generativa, ou GAN). ${ }^{5}$

\section{Especificidade da quarta e da quinta instância para o robô:}

Haverá uma espécie de rascunho ou várias versões, mas a resolução será tão rápida que o engenheiro não será capaz de escrever ou entender os números ou a lógica dos cálculos. Chamei esta instância “o primeiro leitor invisível”. É como se o engenheiro fosse confrontado com uma enorme parede impossível de atravessar atrás da qual a máquina funciona ou como se o mesmo engenheiro estivesse em frente ao mar cujas gotas de água não podem ser calculadas nem entendidas nos seus movimentos.

Quinta instância. O robô decide sozinho e segue seu caminho. Em seguida, continua o diálogo tridirecional abrangendo: o engenheiro-construtor, os dados e o conjunto de metas.

Uma pergunta permanece, no entanto, que me interpela e pede mais desen- 
volvimento (o que não vou fazer aqui): será que posso chamar esse mundo, -o "inconsciente virtual" já que é desconhecido do engenheiro ou "saber virtual inatingível pelo homem" sem fazer alusão à psicanálise? Situo esse "saber virtual inatingível para o homem" no meio da roda da escritura do robô, no lugar do gozo que não existe no robô.

\section{GPT 2 e 3 e a arte}

Os GPTs poderão finalmente escrever como um escritor? Deparei-me com o trabalho de um artista que colabora com a IA em suas criações, Ross Goodwin. Ele dá uma ideia do que poderia ser o papel de IA na criação artística do futuro. Usando uma rede de neurônios artificiais recorrentes (LSTM) ${ }^{6}$ para compor por o filme Sunspring, ele afirma:

[...] que o aumento da criatividade humana é o principal uso dessas máquinas. No entanto, seu uso também pode informar nossa compreensão dos mecanismos semânticos, ou a falta deles, embutidos nas palavras que lemos todos os dias. Nós geralmente consideramos que o trabalho de fazer sentido de palavras é do escritor. No entanto, diante de um texto desprovido de significado objetivo, o leitor assume esse papel. De certa forma, o leitor se torna o escritor (Goodwin, junho de 2016).

O leitor se insere na roda da escritura do robô e substitui a instância do autor que decide o significado. Isso significa que, no caso de um texto produzido por uma máquina, o leitor se juntará ao robô e completará a composição. Em outras palavras, a narrativa do robô precisa da subjetividade do homem para lhe atribuir sentidos.

Ross Goodwin reconhece a ininteligência dos textos gerados pela máquina, que anexa palavras sem entendê-las. Ele compara o texto gerado a uma canção do Prêmio Nobel de literatura em 2016, Bob Dylan, My Back Pages, onde todos a leem ou a ouvem como queiram, embora as frases, corretas gramaticalmente falando, pareçam mais uma montagem de palavras sem sentido no início.

\section{My Back Pages}

Crimson flames tied through my ears

Rollin' high and mighty traps

Pounced with fire on flaming roads

Using ideas as my maps

We'll meet on edges, soon said I

Proud 'neath heated brow

Ah, but I was so much older then

I'm younger than that now

Half-wracked prejudice leaped forth Rip down all hate, I screamed Lies that life is black and white Spoke from my skull, I dreamed Romantic facts of musketeers Foundationed deep, somehow Ah, but I was so much older then I'm younger than that now

Girls' faces formed the forward path From phony jealousy

To memorizing politics

Of ancient history

Flung down by corpse evangelists

Unthought of, though, somehow

$\mathrm{Ah}$, but I was so much older then

I'm younger than that now

A self-ordained professor's tongue 
Too serious to fool

Spouted out that liberty

Is just equality in school

Equality, I spoke the word

As if a wedding vow

Ah, but I was so much older then

I'm younger than that now

In a soldier's stance, I aimed my hand

At the mongrel dogs who teach

Fearing not that I'd become my enemy

In the instant that I preach

My pathway led by confusion boats

Mutiny from stern to bow

$\mathrm{Ah}$, but I was so much older then

I'm younger than that now

Yes, my guard stood hard when abstract threats

Too noble to neglect

Deceived me into thinking

I had something to protect

Good and bad, I define these terms

Quite clear, no doubt, somehow

Ah, but I was so much older then

I'm younger than that now ${ }^{7}$

Em um diálogo com a filha de 9 anos de um de seus amigos, Goodwin consegue definir o papel da arte e do robô. Não resisto a submeter o comentário a vocês:

Saber que o pai dela é Blaise Agaera y Arcas, que lidera uma equipe de inteligência artificial no Google, não é sem importância.

[...] Poucos dias depois de conhecer o pai (em uma convenção), ele me enviou um e-mail de sua filha de 9 anos, que faz parte de um grupo de escritores locais [...]. Ela escreveu o seguinte:

Eu acho que o que você está fazendo é extremamente interessante. No entanto, acho que essa arte engana qualquer um. [...]. Talvez então, Sr. Goodwin, enquanto os dispositivos ainda são relativamente estúpidos, você deve continuar a criar esta arte. [...].
No que é comumente definido como arte real, há dezenas de camadas de significado. Há algo por trás da arte. Imagine uma pilha de papel em uma janela. A folha de cima é o que você vê no início, seu primeiro olhar. Agora, em uma inspeção mais minuciosa, você pode cavar nas camadas de papel, geralmente nunca alcançando a última folha absoluta, mas ainda satisfeito com sua distância de onde você começou a olhar para a sala.

Com sua arte (a das máquinas de Goodwin) há um pedaço de papel em uma janela. Sem camadas. Tudo o que há é o que você vê à primeira vista. A câmera não quis dizer nada quando ela escreveu este poema. Apenas palavras, frases, frases, falas. [...] $O$ dispositivo não era criativo. Ele estava fazendo o que Ihe foi dito para coletar dados e chegar a um resultado, como a matemática. Isso não é poesia de verdade. No entanto, não estou dizendo que nunca será.

$\mathrm{Na}$ minha resposta, expliquei a ela que a obra de arte é o conceito e o dispositivo, não o resultado, e ela parecia mais satisfeita com isso. [...] Espero que isso incentive os jovens a pensar sobre o futuro que estamos criando e como a inteligência artificial se encaixa nesse futuro.

A conclusão parece óbvia. Em princípio, essa máquina nunca poderá substituir o homem na criação literária. $\mathrm{O}$ robô precisa no início de seu fabricante e, apesar de seu poder quase ilimitado de cálculos que lhe permite considerar milhões de possibilidades, ele acumulará frases semanticamente pouco válidas e conexões ilógicas entre essas frases, o que gerará textos que precisam de um leitor ou mil leitores que o interpretem de acordo com seus desejos e emoções. 


\section{O GPT-3 de 175 bilhões de parâmetros que chegou em 2020 seria capaz de escrever um texto?}

Frederik Bussler, chefe da "Obviamente IA" (OBIUS IA) promete mais desempenho. Seu site e blog valem um desvio para ver até onde a nova máquina pode ir. (Bussler, 2020) Diferente do GPT-2 que imita uma melodia ou um texto, o GPT-3 desenvolve um assunto sugerido pelo engenheiro, como uma poesia, uma melodia ou um artigo:

Por exemplo, se você quiser gerar uma notícia, você pode inserir um título como "Os metodistas unidos aceitam a separação Histórica" e um subtítulo como "Aqueles que se opõem ao casamento gay formarão sua própria denominação". Com essa sugestão, o GPT-3 deu o seguinte:

"Após dois dias de intenso debate, a Igreja Metodista Unida aceitou uma divisão histórica - que deve terminar com a criação de uma nova denominação, que será "teologicamente". e socialmente conservador", segundo o Washington Post. A maioria dos delegados presentes na conferência geral anual da Igreja em maio votou para fortalecer a proibição da ordenação do clero LGBTQ e para elaborar novas regras que "disciplinarão" o clero que oficializa casamentos entre pessoas do mesmo sexo. Mas aqueles que se opuseram a essas medidas têm um novo plano: dizem que formarão uma denominação separada até 2020, chamando-se Igreja metodista cristã..."
Submetido a uma pesquisa de opinião, apenas $12 \%$ afirmaram corretamente que isso foi escrito por uma IA. 88\% foram enganados. Não é incrível? O GPT-3 poderia substituir um jornalista como Josué Guimarães?

E se fosse literatura? Bussler responde: com o GPT-3 você se engaja em um diálogo e escreve instruções para ensinar ao GPT-3 o que você quer. [...]

O GPT-3 não cria, mas segue as instruções de seu inventor; não é autossuficiente; o scriptor será duplo, um dará as instruções e o segundo as executará, e assim para cada rasura onde o inventor reavalia o resultado e deixa em seguida o robô continuar ou não.

No entanto, o GPT-3, lendo as instruções, pode adaptar de forma flexível seu estilo de escrita e raciocínio e usar novas definições ou regras ou palavras definidas na entrada de texto, mesmo que nunca as tenha visto antes.

Quanto à qualidade de sua poesia, segundo Bussler, o GPT-3 impressiona com sua qualidade que "parece superar a de quase todos os poetas adolescentes",. O instrutor tem que seguir passo a passo a construção do poema solicitado. Em seu blog https://www.gwern.net/GPT-3, Bussler dá vários exemplos, incluindo o da imitação do poema de Poe, The Raven / O Corvo. Deixei em itálico a tradução do original, $\mathrm{O}$ robô continua o poema, misturando versos de sua invenção: 
"Essas visões solenes mais longe,

Eu gostaria de desfrutar do meu conhaque em torno da minha casa solitária.

Devo então convocá-lo,

Para atender a chamada da cortina?

Só isso, e nada mais?

Eu então empurrei a veneziana e com uma batida tumultuada de asas,

entrou um corvo majestoso digno dos velhos tempos. ${ }^{8}$

Ah, não! Que eu tinha olhado para ele mais de perto!

Mas minha alma ficou dormente [...]

: "Eu acho que se a sua creta é um pouco grosseira, você, meu filho, não foi mal nomeado." "Nunca mais", disse o corvo ${ }^{9}$

O comentário de Bussler é surpreendente

Mas então algo aconteceu. A escrita do poema, embora utilitária, tornou-se estranhamente emocional. [..]. Voltei e li o artigo em voz alta, e foi incrivelmente evocativo. Eu quase podia imaginar que as estrofes úmidas e misteriosas eram assustadoras. Minha mente começou a se empolgar enquanto eu lia.[...] Senti como se não estivesse lendo um programa, eu era um poeta. [...] Eu me vi fascinado pelo ritmo, pela cadência, pelas delicadas nuances da frase[...] O programa de computador tinha criado mais do que apenas um poeta. Ele tinha criado um artista. [...]. Criei uma voz para o humano desconhecido que se esconde no binário. Criei um escritor, um escultor, um artista.

Responderei a Bussler que ele não criou um escritor nem revelou "uma voz que se esconde no binário", mas um programa que se torna no máximo um auxílio fantástico ou um colaborador eminente que, embora sem autonomia suficiente, não será igual ao homem tão cedo. Mesmo que aprendesse a aprender com o meta-aprendizagem, manteria sua dependência até o fim, incluindo a do inconsciente de seu inventor.

Talvez possamos considerar o GPT3 como uma criança que inicialmente recebe instruções do adulto para o jogo de xadrez e que, em seguida, com sua inteligência ou sua maneira de combinar as peças, encontra sozinho os passos a seguir para bater seu oponente? Direi que a comparação é boa, mas limitada no tempo.

Enquanto a criança vai se virar e aprenderá na medida que ele tocará o jogo, o robô vai precisar de instruções de tempos em tempos ou outros trechos do original para prosseguir, portanto de outro ou de um sujeito.

A mais, não será capaz de ouvir os desejos da comunidade ou mesmo do mundo e não responderá às suas ansiedades do momento. Relacionar informações não fará com que ele consegue captar o que interesse o público.

E uma falsa instrução vai levá-lo a um caminho sem saída, comenta Bussler: "O GPT-3 pode "falhar" se uma instrução estiver mal escrita, não incluir exemplos suficientes ou se parâmetros de amostragem ruins forem usados [...] [...] as declarações devem ser verdadeiras, informativas e relevantes" 
Ele conclui:

O desempenho impressionante do GPT-3 convenceu muitos de que a superinteligência está mais próxima do que pensamos ou pelo menos que o código gerado pela IA está mais próximo do que pensamos. Gera conteúdo criativo, perspicaz, profundo e até magnífico.

Mas eu pergunto: A superinteligência é medida pelo grau de informação conhecida? Se acreditarmos nisso, a máquina do Google é mais esperta do que qualquer homem, fosse Einstein.

A inteligência não se mede por testes, mas por sua capacidade de se adaptar ao ambiente e criar condições para viver nesse ambiente, quero dizer, saber relacionar o que sinto e o que me cerca e no mesmo sentido, estabelecer relações desconhecidas entre, por exemplo, uma fórmula $\mathrm{E}=\mathrm{MC}^{2} \mathrm{e}$ o universo.

Questiono também a autonomia do GPT-3; o programa parece construído para seguir instruções e não para inovar. Seu instrutor serve como um retransmissor.

Sem seu informante que dá o clique para a criação, ele permanece inerte $\mathrm{e}$ sem vida. Embora com um poder mil vezes maior que seus antecessores, ele continua dependente do homem.

Embora seja seguro dizer que a GPT-3 seja definitivamente o início de muitas descobertas inovadoras no mundo do aprendizado de máquina e de fato, é, será que posso manter a posição adotada após o estudo do GPT-2 e do GPT-3 com o novo GPT chinês, o Wu Dao 2.0. de 1,75 trilião de parâmetros (10x GPT-3) que chegou em 2021?

Será que posso manter o que dizia no final da conferência no Colóquio?

"qualquer GPT, por mais poderoso que seja, não será capaz de criar como o homem, isto é, "somatisar o improvável", ${ }^{10}$ não tendo corpo nem possuindo subjetividade, assim, não poderá seguir completamente as instâncias da roda da escritura No máximo, ele ajudará o artista, e nosso caso, o escritor ou o poeta a encontrar elementos originais na enorme rede de informações que ele domina."

$\mathrm{O} \mathrm{Wu}$ Dao 2.0 conseguiria vencer todos os obstáculos e incluir a subjetividade do homem com o trilhão e meio de parâmetros? É o que afirma o Dr. Zhang Hongjiang, presidente de "Beijing of Artificial Intelligence":

Esses modelos sofisticados, treinados em conjuntos de dados gigantescos, exigem apenas uma pequena quantidade de novos dados quando usados para um recurso específico, pois podem transferir conhecimento já adquirido para novas tarefas, assim como os seres humanos. [...] Modelos pré-treinados em larga escala são hoje um dos melhores atalhos para a inteligência artificial geral.

Por outro lado, o pesquisador Tang Jie destacou as habilidades de Wu Dao 2.0 em "criação de poesia, dísticos, resumos de texto, questões e respostas de cenário humano, pintura" e até mesmo reconheceu que o sistema "esteve perto de quebrar o teste de Turing, ${ }^{11} \mathrm{e}$ competindo com os humanos. ${ }^{12 "}$ 
Como não temos ainda provas suficientes da capacidade dessa máquina, continuo duvidando que uma máquina saiba percorrer a roda da escritura como um sujeito humano que dispõe de um cérebro fantástico e de um inconsciente. Assim, ficamos com dúvidas e aguardamos os resultados concretos da máquina para encaminhar respostas melhores nessa luta entre máquinas e o ser humano.

\section{Art and Artificial Intelligence Programs: GPT-2, GPT-3, Wu Dao 2.01}

\section{Abstract}

The text is part of a research trying to relate the study of the manuscript with artificial intelligence. From the deed wheel, I check on which measures the GPT and Wu Dao 2.0 programs can follow the wheel or not. If for GPT 2 and 3, it seems of course that not having subjectivity, it is impossible to go through the wheel, we are in doubt as to the Chinese program due to the enormous capacity never seen until today.

Keywords: GPT-2, GPT-3, Wu Dao 2.0, genetics, breeding processes

\section{Notas}

1 Conferência transmitida online no colóquio "100 anos de JOSUÉ GUIMARÃES n Universidade de Passo Fundo, dia 3 de maio de 2021.

2 Willemart, Signum, Estudos da Linguagem, Londrina, v. 23 , n. 2 , p. $10-22$, ago. 2020
3 Google's Artists and Machine Intelligence program https://ami.withgoogle.com/

4 GPT-3 (Generative Pre-Training Transformer ) é um programa de computador criado por uma start-up de São Francisco, OpenAI (financiada entre outros por Elon Musk). É uma enorme rede neural com 175 biliões de parâmetros (O GPT-2 de 2019, tinha apenas 1,5 bilião de parámetros).e, como tal, o GPT3 faz parte do segmento deep learning de Machine Learning.

5 Em inteligência artificial, as redes contraditórias geradoras (GANs) são uma classe de algoritmos de aprendizagem não supervisionados. Esses algoritmos foram introduzidos por Goodfellow et al. 2014. Eles podem gerar imagens com um alto grau de realismo. A GAN é um modelo generativo onde duas redes são colocadas em competição em um cenário de teoria de jogo1. A primeira rede é o gerador, gera uma amostra (por exemplo, uma imagem), enquanto seu oponente, o discriminador tenta detectar se uma amostra é real ou se é o resultado do gerador. $\mathrm{O}$ aprendizado pode ser modelado como um jogo de soma zero1. Aprender essas redes é difícil na prática, com problemas significativos de não convergência. Wikipédia

6 Long short-term memory (LSTM) est un réseau de neurones artificiels présentant des connexions récurrentes. Un réseau de neurones récurrents est constitué d'unités (neurones) interconnectées interagissant non-linéairement et pour lequel il existe au moins un cycle dans la structure. Les unités sont reliées par des arcs (synapses) qui possèdent un poids. La sortie d'un neurone est une combinaison non linéaire de ses entrées. Wikipedia

7 Dylan, https://www.letras.mus.br/bob-dylan/ 103350/ traducao.html

8 Only this, and nothing more?"

Open here I flung the shutter, when, with many a flirt and flutter,

In there stepped a stately Raven of the saintly days of yore.

9 "Quoth the Raven, "Nevermore."

And the Raven, never flitting, still is sitting, still is sitting

On the pallid bust of Pallas just above my chamber door;

And his eyes have all the seeming of a demon's that is dreaming,

And the lamp-light o'er him streaming throws his shadow on the floor;

And my soul from out that shadow that lies floating on the floor

Shall be lifted-nevermore! 
10 Sloterdijk, 2015, p.181

11 O Teste de Turing testa a capacidade de uma máquina exibir comportamento inteligente equivalente a um ser humano, ou indistinguível deste. No exemplo ilustrativo original, um jogador humano entra em uma conversa, em linguagem natural, com outro humano e uma máquina projetada para produzir respostas indistinguíveis de outro ser humano. Todos os participantes estão separados um dos outros. Se o juiz não for capaz de distinguir com segurança a máquina do humano, diz-se que a máquina passou no teste. $O$ teste não verifica a capacidade de dar respostas corretas para as perguntas; mas sim o quão próximas as respostas são das respostas dados por um ser humano típico. A conversa é restrita a um canal de texto, como um teclado e uma tela para que o resultado não dependa da capacidade da máquina de renderizar áudio.

$\mathrm{O}$ teste foi introduzido por Alan Turing em seu artigo de 1950 "Computing Machinery and Intelligence", que começa com as palavras: "Eu proponho considerar a questão 'As máquinas podem pensar?". Já que "pensar" é difícil de definir, Turing preferiu "trocar a pergunta por outra, a qual está relacionada à anterior, e é expressa em palavras menos ambíguas". A nova pergunta de Turing é: "Há como imaginar um computador digital que faria bem o 'jogo da imitação?". Turing queria que esta questão pudesse ser respondida. No restante do artigo, ele argumenta contra as principais objeções à proposta que "máquinas podem pensar" o cientista afirmou ainda que, se um computador fosse capaz de enganar um terço de seus interlocutores, fazendo-os acreditar que ele seria um ser humano, então estaria pensando por si próprio.

Muitos eventos que visaram a utilização prática do Teste de Turing já ocorreram, como o Loebner Prize, que acontece anualmente desde 1990 e é dito como o "primeiro teste de Turing".Há controvérsias se os testes desses eventos são ou não válidos.Wikipedia.

12 https://towardsdatascience.com/gpt-3-scared-you-meet-wu-dao-2-0-a-monster-of-1-75-trillion-parameters-832cd83db484, consultado de junho de 2021.

\section{Referências}

Bussler, Frederik,. https://www.gwern.net/ GPT-3

Dylan., Bob, https://www.letras.mus.br/bob-dylan/103350/traducao.html

Goodwin, Ross, https://medium.com/artistsand-machine-intelligence/adventures-in-narrated-reality-part-ii-dc 585af054cb

Google's Artists and Machine Intelligence program https://ami.withgoogle.com/

Sadin, Éric, La vie algorithmique. Critique de la raison numérique. Paris : éd. L’Échappée, 2015

Sloterdijk, Peter, Tu dois changer ta vie. Paris : Fayard-Pluriel, 2015

Willemart, Philippe, A escritura na era da indeterminação, São Paulo, Perspectiva, 2019

-.Inteligência artificial e Arte, Signum, Estudos da Linguagem, Londrina, v. 23, n. 2, p. 10-22, ago. 2020

Wu Dao 2.0 https://towardsdatascience.com/ gpt-3-scared-you-meet-wu-dao-2-0-a-monster-of-1-75-trillion-parameters-832 cd83db484, 